American J. of Engineering and Applied Sciences 2 (2): 372-380, 2009

ISSN 1941-7020

(C) 2009 Science Publications

\title{
Protection for an Immediate Split Structure of Tree-Based EPON Architecture-Ideal Condition Analysis
}

\author{
Mohammad Syuhaimi Ab-Rahman, Siti Asma Che Aziz and Kasmiran Jumari \\ Department of Electrical, Electronic and Systems Engineering, \\ Faculty of Engineering and Built Environment, University Kebangsaan Malaysia, \\ 43600 UKM Bangi, Selangor, Malaysia
}

\begin{abstract}
Problem statement: Ethernet Passive Optical Network (EPON) was proposed to overcome the bandwidth bottleneck at the Access Networks due to its simplicity, cost effective and wide spread deployment. A failure in access networks can cause serious problems, because access network transmit aggregated high speed traffic from hundreds of subscribers. Protection and restoration mechanisms have been applied in backbone networks, but access networks are not considered significantly in the scope of survivability. Approach: In this study, we proposed a cost effective protection scheme for a novel tree-based EPON architecture. Immediate Split Structure (ISS) means the signal was totally split after pass through the first optical splitter. This was the second proposal method after first suggestion using Optical Cross Add and Drop Multiplexer (OXADM) as a restoration switch. In this study we used only $2 \times 2$ and $2 \times 1$ optical switches combination to divert the traffic to the alternative path. Three faulty conditions were considered in this research and OptiSystem, Inc software was used to prove the solution feasibility. Results: The Bit Error Rate (BER) performances were measured by a $1.25 \mathrm{~Gb} \mathrm{sec}^{-1}$ Non-Return-to-Zero (NRZ) pseudo random binary sequence (PRBS) with a pattern length of $2^{31-} 1$ for the downstream traffic between the OLT and 8 ONUs. Our results were obtained by observing bit error rates, eye diagrams and optical power levels in ideal condition. Conclusion: The survivability of EPON is necessary to provide seamless services and ensure network reliability. Single failure in the line connected will activate dedicated protection while shared protection was activated when both fiber (working and standby fiber) are breakdown. We analyzed the system in ideal condition to prove the system feasibility.
\end{abstract}

Key words: EPON, ISS, OXADM, protection, restoration

\section{INTRODUCTION}

New broadband deployments are frequently justified primarily by today's applications rather than anticipated demands. For example, streaming video content is considered by many as the ultimate bandwidth-hungry application. When one adds the bandwidth requirements of one high-definition TV stream, a few standard-definition streams and Internet browsing, it may seem that 20-25 Mbit $\mathrm{sec}^{-1}$ of bandwidth is sufficient in the long term. But historical data and projections indicate exponential long-term growth in bandwidth demand. Indeed, some service providers are already offering $1 \mathrm{Gbit} \sec ^{-1}$ access to residential customers today and there are substantial deployments of $100 \mathrm{Mbit} \mathrm{sec}^{-1}$ networks in some European countries. These bit rates can only be provided via FTTH. FTTP allows the service provider to branch out being a single service delivery company to participating in various consumer activities with potentially attractive revenue streams, ranging from communications, to entertainment, to information. It has long been thought that fiber's very significant bandwidth would open the way to new applications by the consumer, but it is only recently with the advent of the Internet and the expansion of copper based broadband that this vision may become reality. The transmission in a PON is performed between an Optical Line Terminal (OLT) installed in a $\mathrm{CO}$ (or remote terminal) and an Optical Network Terminal (ONT) placed at the customer residence or in a building. The OLT is an active equipment. It corresponds to the demarcation point between the access network and the metro backhaul network ${ }^{[1]}$.

Corresponding Author: Mohammad Syuhaimi Ab-Rahman, Department of Electrical, Electronic and Systems Engineering, Faculty of Engineering and Built Environment, University Kebangsaan Malaysia, 43600 UKM Bangi, Selangor, Malaysia 
Ethernet based Passive Optical Network (PON) technology is emerging as a viable choice for the nextgeneration broadband access network ${ }^{[2,3]}$. EPON is a PON that carries Ethernet traffic. PON is a point-tomultipoint fiber optical network with no active elements in the signal's path. All transmissions in a PON are between an Optical Line Terminal (OLT) of Central Office (CO) and Optical Network Units (ONUs). Traffic from an OLT to an ONU is called 'downstream' (point-to-multipoint) and traffic from an ONU to OLT is called 'upstream' (multipoint-to-point). Two wavelengths are used: typically $1310 \mathrm{~nm}$ for the upstream transmission and $1490 \mathrm{~nm}$ for the downstream transmission. In the downstream direction (OLT to user), are broadcasted by the OLT and extracted by their destination ONUs based on their Media Access Control (MAC) address. In the upstream direction (user to OLT), each ONU will use a time shared channel (TDM) arbitrated by the OLT. Since the PON connectivity in a FTTH access network can accommodate a large number of subscribers, when any fault occurs at one point in an optical fiber line, the network will without any function behind the break point. It leads to affect the whole services transmission. The upstream signal from multiple Optical Network Units (ONUs) at different residential locations to OLT and $\mathrm{CO}$ or the downstream signal from OLT to multiple ONUs after the break point will become unreachable if the fault occurs in the drop region. However, if the fault occurs in an individual subscriber's infrastructure such drop fiber or ONU, since the signals from OLT are successfully shared among other subscriber's ONUs via a passive optical splitter, thus only one subscriber's service is affected.

In this study we proposed the restoration architecture that can be applied in FTTH EPON especially in drop region (optical splitter to ONU). Any failure occurs in this region will be switched the traffic to the alternative path according to the types of failure. Failure in single working line will divert the signal to protection fiber that bundled together in one single cable. But if failure occurs on cable (both fiber damage) has to switch the signal to the other alternative protection line of neighbor connection. The first restoration scheme named as linear protection and the latter is shared protection. Both scheme proposals on survivability have aimed on ensuring the traffic flow continuously from OLT to ONU. This can be done by wisely and well-planned on fiber installation during FTTH deployment.

Tree-based architecture-Immediate split structure: The transmission in a PON is performed between an
Optical Line Terminal (OLT) installed in a CO (or remote terminal) and an Optical Network Terminal (ONT) placed at the customer residence or in a building. The OLT is an active equipment. It corresponds to the demarcation point between the access network and the metro backhaul network. The ONT is the active interface between the broadband access network and the customer's phone, computer and TV etc. This equipment performs among others functionalities optical-to-electrical conversion (and vice versa). In the GPON technology, passive optical components (optical splitter or tap coupler) are placed between the two active equipments. By this way, one optical fiber is passively split between multiple ONT's who share the capacity of one fiber. The fiber between the OLT and the passive splitting node is defined as the feeder fiber and distribution fiber corresponds to the portion of the local loop between the passive coupler and the ONT. Immediate Split Structure (ISS) only uses one optical splitter to distribute the signal to all premises. This type of architecture normally used for apartment, small offices and outlets which share one building. Due to the distance between each user is near possibly the restoration scheme can able be implemented easily.

Non secured PON architectures: Basically, three architectures may be deployed for the fiber access network. The three architectures are point to point architecture, active star architecture and passive star architecture $^{[4]}$. Fig. 1 shows the architecture of FTTH point to multipoint. Availability and cost results are very sensitive to feeder and distribution lengths. These lengths are reported for three distinct areas: Dense urban, semi urban and rural. This choice is based on distances encountered in Europe. In case of dense urban, the tree architecture seems more suitable whereas bus architecture can be considered in case of rural area. For the bus architecture, the feeder fiber is the optical part between the OLT and the first splitting node.

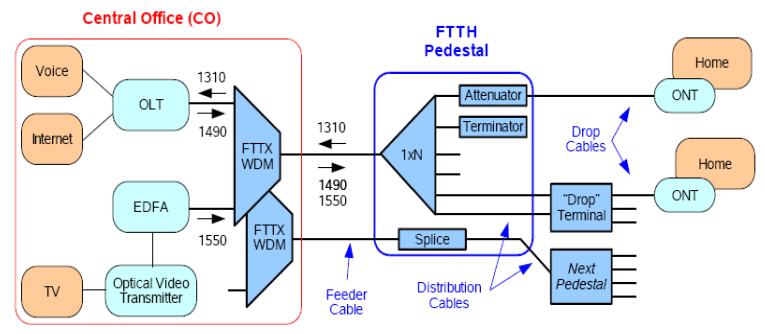

Fig. 1: Point to multipoint architectures 
The fiber between the ONT and the corresponding splitting node and the fiber between two adjacent splitting nodes correspond to the distribution fiber. For the semi urban area, the calculations were realized considering bus and tree architectures.

Protection against equipment and cable failures in the access networks is crucial to ensure continuous services to the end-users in particular in case of lifeline services supplying. These architectures based in the majority on the tree architecture are issued from the IUT-T G984.1 recommendation ${ }^{[5]}$. In the first configuration fiber duplex architecture, a spare fiber is equipped between the OLT and the splitter coupler. In case of fiber failure, the PON interface detects the failure and switches the signal to the spare fiber. This architecture is attractive as it permits to protect the most widely shared section that is the feeder fiber. In the second configuration protection against feeder fiber failure and PON interfaces failure in the OLT are assured. The splitter has in this case two input/output ports on the OLT side (N:2 optical splitter). The standby PON interface is activated when the working PON interface fails.

In the ring architecture a ring structure permits to protect the elements constituting the ring that are optical feeder fiber and PON interfaces at OLT side. In the full redundant all the network components are doubled. In this configuration, failure at any point can be recovered by switching to the standby facility. This architecture is the only architecture which protects all the optical paths. For the other architectures the protected section extends at the most from the OLT to the optical splitter or the tap coupler closest to the customer. This full redundant architecture should permit to propose traffic prioritization. If traffic prioritization is implemented, high priority traffic is transmitted on the primary path whereas the best effort traffic is diffused on the backup path. In case the primary path breaks, the high priority traffic is transferred to the backup path.

\section{MATERIALS AND METHOD}

Figure 2 shows the mechanisms of protection in FTTH-PON access network in normal condition and different breakdown locations. Green arrow shows the normal condition when there is no breakdown occurs for both working line and protection line. Purple arrow shows the mechanism of dedicated protection in FTTH access network when there is breakdown occurs at working line. Orange arrow shows the mechanism of shared protection in FTTH access network when there is breakdown occurs at both working line and protection line.

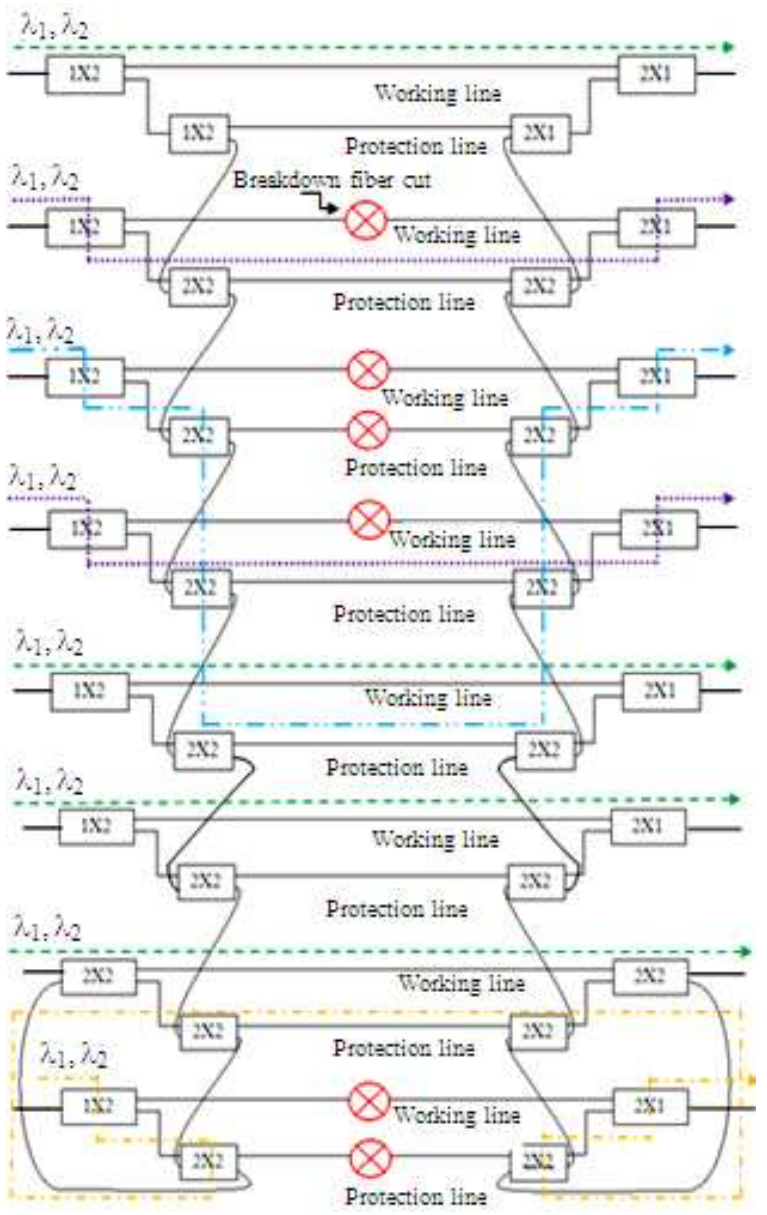

Indicator:

---- : Normal condition

......... : Breakdown at working line

$-\cdot-\cdot \rightarrow$ : Breakdown at working line and protection line

$-\cdots \rightarrow$ : Breakdown at working line, protection line and working line neighbor

Fig. 2: protection route mechanism in PON-FTTH

This mechanism of protection will find the near neighbor protection line. Blue arrow shows the another mechanism of shared protection in FTTH access network when there is breakdown occurs at both working line and protection line and also breakdown at working line neighbor. This mechanism of protection will find the neighbor protection line with good condition. The FTTH based network design was modeled and simulated using the Optisystem CAD program by Optiwave System, Inc. The receiver is a PIN photodetector with $-25 \mathrm{dBm}$ from the simulation result. The specifications of components in this model are tabulated in Table 1. 
Am. J. Engg. \& Applied Sci., 2 (2): 372-380, 2009

Table 1: Simulation parameter

\begin{tabular}{lll}
\hline Component & Parameter type & Value \\
\hline PBRS generator & Upstream Bit rate (Gbps) & 1.25 \\
& Downstream Bit rate (Gbps) & 1.25 \\
& & (Symmetrical) \\
Electrical generator & Rise time/ fall time & 0.05 bit \\
Light source & Downstream wavelength (nm) & 1480,1550 \\
& Upstream wavelength (nm) & 1310 \\
Modulator & Modulation format & NRZ \\
Multiplexer/demultiplexer & Insertion loss (dB) & 0.5 \\
Bidirectional splitter (1:8) & Insertion loss (dB) & 5 \\
Circulator bidirectional & Insertion loss (dB) & 1 \\
Bidirectional optical fiber & Attenuation constant $\left(\mathrm{dB} \mathrm{km}^{-1}\right)$ & 0.25 \\
SMF $(2 \mathrm{~km})$ & Attenuation constant $\left(\mathrm{dB} \mathrm{km}^{-1}\right)$ & 0.25 \\
\hline
\end{tabular}

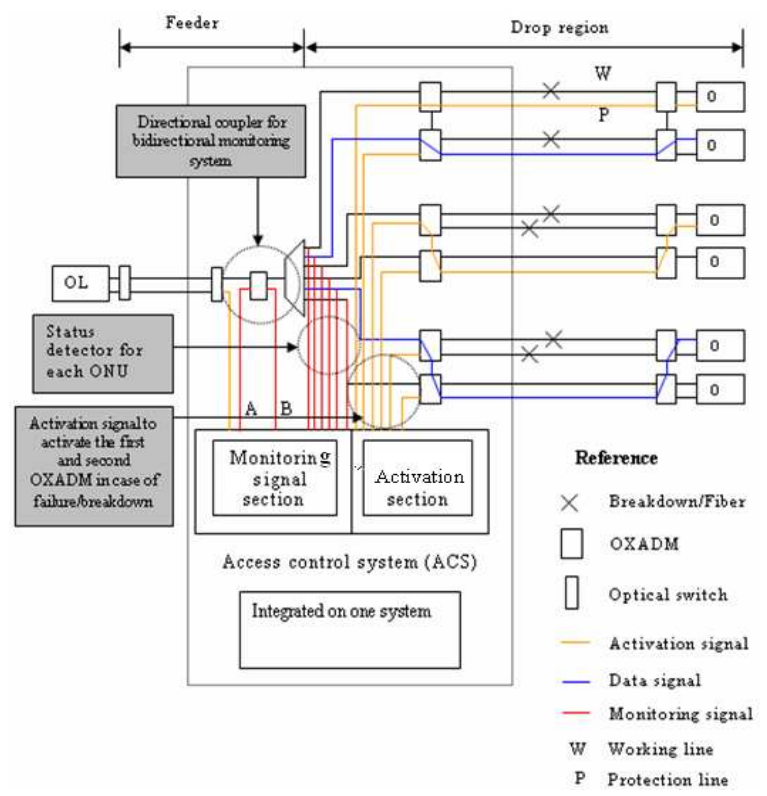

Fig. 3: Architecture of restoration in FTTH access network centralizing at ACS which control the monitoring subsystem and restoration activation

Failure detection: Due to lack of active devices in FTTH network, the functions of ONUs are passively and don't provide any sensor related to fault or breakdown. To overcome the incomplete in FTTH technology, Access Control System (ACS) is introduced to control the survivability in FTTH access network. ACS is used to monitor the status of the working and restoration fibers ${ }^{[6]}$. The unique monitoring system architecture requires a single switch element and coupler connection between the ACS and both transmission paths. Before activating a suitable protection scheme, ACS will recognize the types of failure and send the activation signal to the related OXADM switches according to the activated protection mechanisms. The architecture of ACS is shown in Fig. 3.
Table 2: Possible status of tapping signal A and B and related fault diagnoses

\begin{tabular}{lcl}
\hline A & B & Diagnose \\
\hline $\mathrm{O}$ & $\mathrm{O}$ & Both feeder and drop region are in good condition \\
$\mathrm{X}$ & $\mathrm{O}$ & Fault occurs in feeder region, No fault in drop region \\
$\mathrm{O}$ & $\mathrm{X}$ & No fault in feeder region, Fault occurs in drop region \\
$\mathrm{X}$ & $\mathrm{X}$ & Both feeder and drop region are in breakdown \\
\hline $\mathrm{X}$ : No signal detected; O: Signal detected
\end{tabular}

It consists of two major parts, monitoring signal section and activation section. The function of ACS is the same as the Optical Performance Monitor (OPM) which is applied in both ring and mesh metropolitan network. Normally, ACS is integrated in a single system, which also includes splitter and first OXADM of each access line. Tapping 3\% of the downstream and upstream signal by using coupler can recognize the status of feeder section and drop section. If breakdown occurs in feeder section, ACS will send a signal to activate the dedicated protection scheme. But if the breakdown is the detected in drop section, ACS will recognize the related access line by the $3 \%$ tapped signal that is connected to every access line. The activation signal is then sent to active the dedicated protection scheme. But if fault is still not restored, the shared protection scheme will be activated. The monitoring signal section is responsible for sensing fault and its location whereas generation of activation of signal is sent by activation section in ACS. Table 2 describes the possible condition in the monitoring system captured from tapped signal and diagnosis of the fault. The couplers will tap 3\% of the downstream and upstream signal in turn and sending it to ACS for interpretation. The condition of the tapped signal will represent the status of feeder section and drop section. ACS will determine the mechanism of protection by detecting and analyzing the monitored signal to the end of restoration process. All is described in the flowchart in Table 2.

Protection mechanism type A: Downstream optic signal with $\lambda_{1}=1480 \mathrm{~nm}$ and $\lambda_{2}=1550 \mathrm{~nm}$ wavelength will be transmitted from central office (OLT) through the feeder region. Then the optic signal $\lambda_{1}$ and $\lambda_{2}$ will enter the drop region after passing through the optical splitter. So, the optic signal will be divided into 8 route signal in the drop region. Fig. 4 represents the green arrow that shows the normal network condition when there is no failure occurs in working line.

Protection mechanism type B: Fig. 5 shows the failure is detected in working line, protection mechanism will be activated and convert the optic signal direction to the protection line. The purple arrow shows the protection mechanism as dedicated protection. 


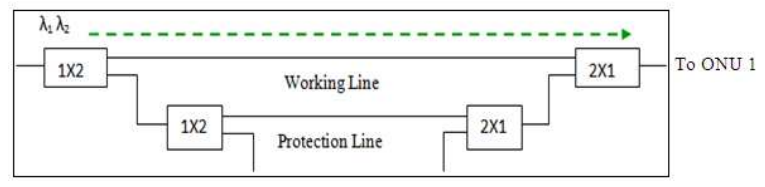

Fig. 4: Protection mechanisms in ideal condition

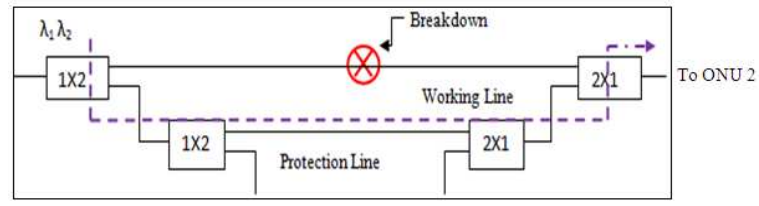

Fig. 5: Breakdown at working line and signal diverted to the protection line

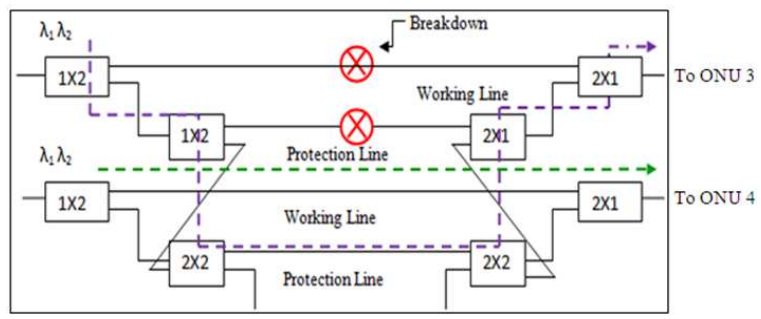

Fig. 6: Breakdown at working line and protection line. Signal diverted to the neighbor protection line

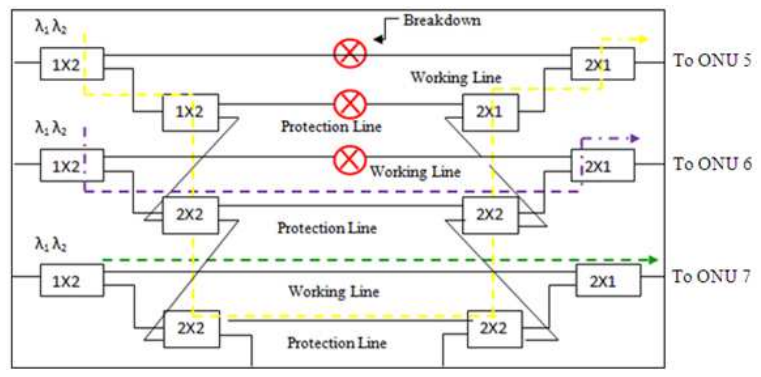

Fig. 7: Breakdown at working line, protection line, working line neighbor

Protection mechanism type C: Figure 6 shows the shared protection scheme when breakdown occurs in both line in working line and protection line. Shared protection scheme will be activated and optic signal will be switched to neighbor line protection as depicted in blue arrow.

Protection mechanism type D: Figure 7 shows the breakdown occurs in both lines and shared protection scheme will be activated and the signal will be routed to the next neighbor protection line. However when the failure also occurs in the neighbor working line, then the mechanism design protocol will give priority for dedicated protection and the signal will be routed to the next neighbor line protection which is in normal condition as in green arrow. The yellow arrow represent the protection mechanism which convert the optic signal to the second neighbor protection line as the first neighbor protection used for dedicated protection (purple arrow).

\section{RESULTS}

Eye diagrams are a very successful way of quickly and intuitively assessing the quality of a digital signal. Downstream optic signal with $\lambda_{1}=1480 \mathrm{~nm}$ and $\lambda_{2}=1550 \mathrm{~nm}$ wavelength will be transmitted from central office (OLT) trough the feeder region. Then the optic signal $\lambda_{1}$ and $\lambda_{2}$ will enter the drop region after passing through the optical splitter. So, the optic signal will be divided into 8 route signal in the drop region.

Protection type A: Fig. 8 shows the eye diagram for downstream wavelength with Max Q Factor and minimum BER value for three different wavelengths measured at ONU 1.

Protection type B: Figure 9 shows the eye diagram for downstream wavelength with Max Q Factor and minimum BER value at the receiver part (ONU 2). In ideal condition, all the failure type will produce nearly same value of Max Q Factor and Min BER value. In ideal condition, insertion loss of the optical switches has not been considered in the simulation parameter and thus will result the same opening eye diagram for all failure condition type.

Protection type C: Figure 10 shows the eye diagram for downstream wavelength with Max Q Factor and minimum BER value at the receiver part (ONU 3). At this line, optic signal will pass through six numbers of optical switches before the signal reach back to the original path. Figure 11 shows eye diagram when the optic signals pass through the working line directly until it reach to the receiver path.

Protection type D: Figure 12 shows the eye diagram for downstream wavelength with Max Q Factor and minimum BER value at the receiver part (ONU 5). Before the optic signal reach to the receiver part, it pass through eighth numbers of optical switches. 
Am. J. Engg. \& Applied Sci., 2 (2): 372-380, 2009

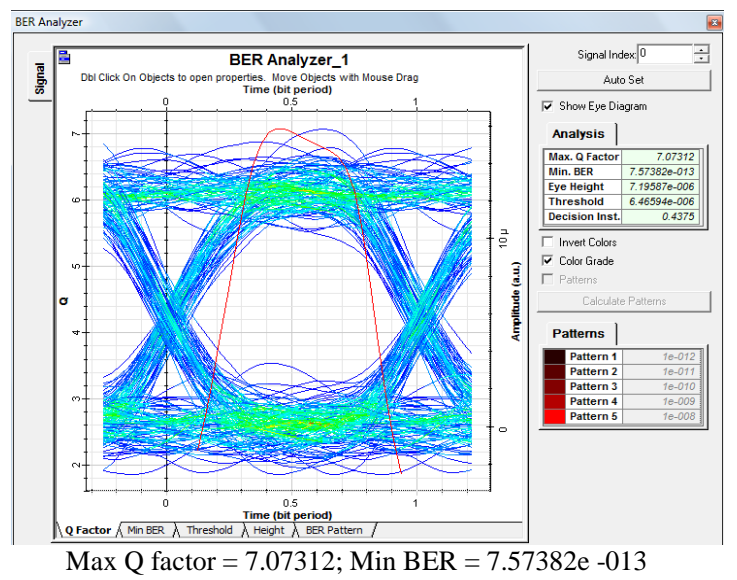

(a)

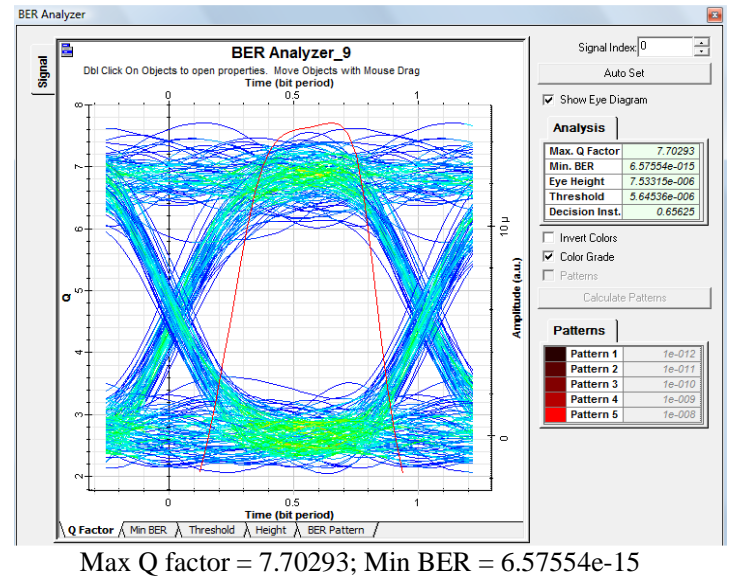

(b)

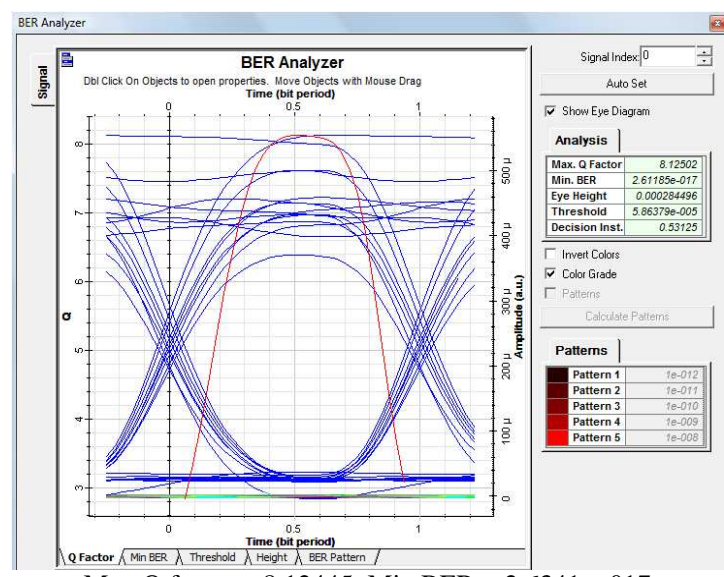

Max $\mathrm{Q}$ factor $=8.12445 ;$ Min BER $=2.6341 \mathrm{e}-017$

(c)

Fig. 8: (a): Max Q factor and min BER at ONU 1 for downstream $1550 \mathrm{~nm}$ wavelength, (b): Max $\mathrm{Q}$ factor and min BER at ONU 1 for downstream $1480 \mathrm{~nm}$ wavelength (c): Max Q factor and Min BER at ONU 1 for upstream $1310 \mathrm{~nm}$ wavelength.

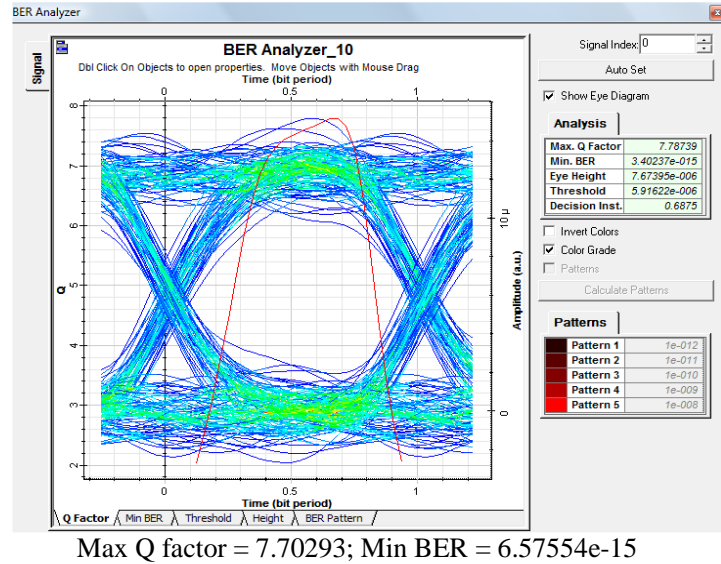

(a)

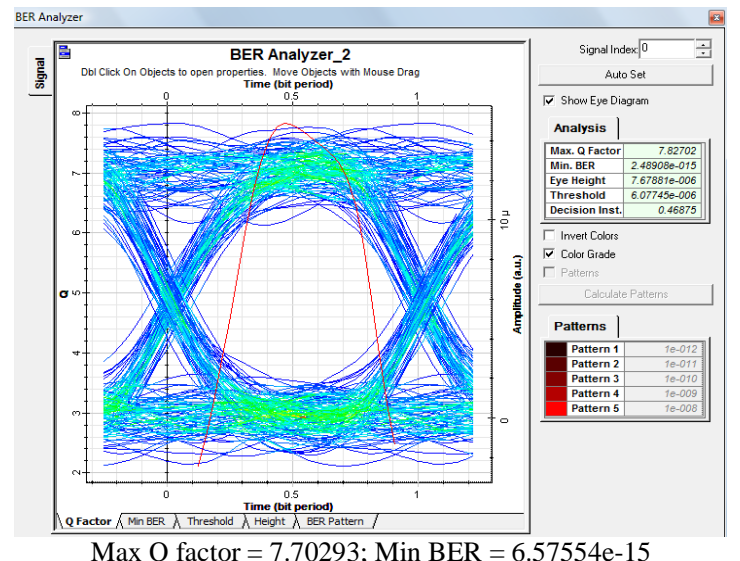

(b)

Fig. 9: (a): Max Q factor and min BER at ONU 2 for downstream $1550 \mathrm{~nm}$ wavelength; (b): Max $\mathrm{Q}$ factor and min BER for downstream $1480 \mathrm{~nm}$ wavelength for mechanism type B. 
Am. J. Engg. \& Applied Sci., 2 (2): 372-380, 2009

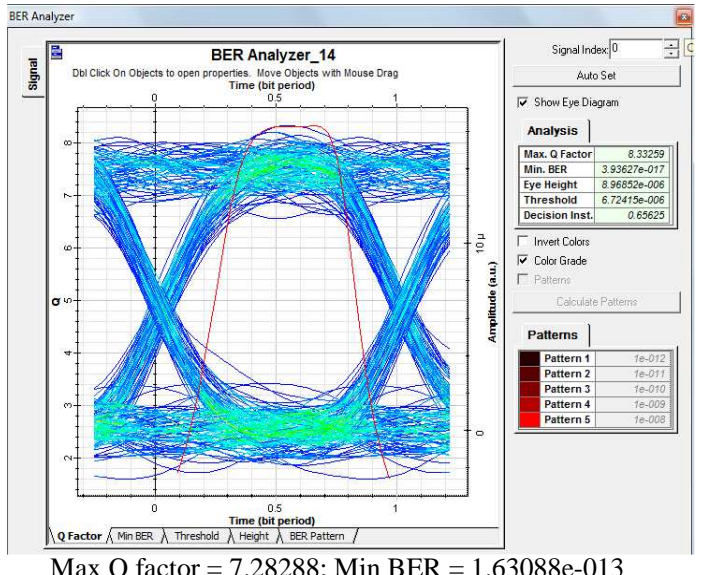

Max Q factor $=7.28288 ;$ Min BER $=1.63088 \mathrm{e}-013$

(a)

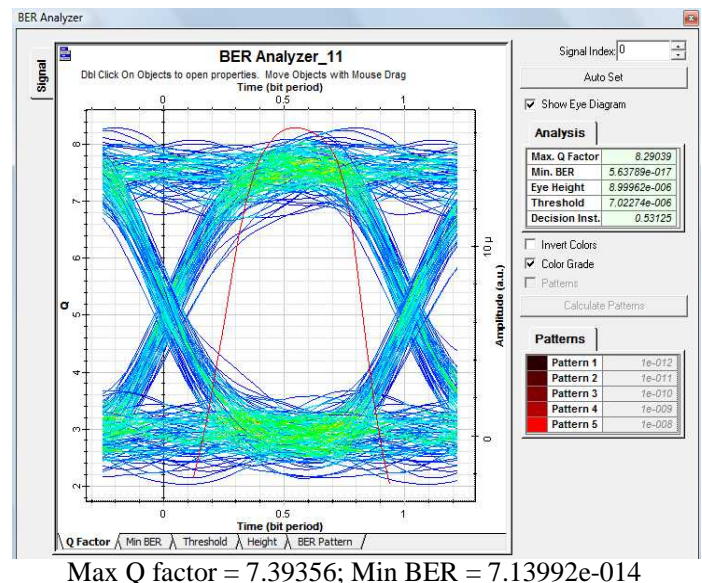

(b)

Fig. 10: (a): Max Q factor and min BER at ONU 3 for downstream $1550 \mathrm{~nm}$ wavelength; (b): Max $\mathrm{Q}$ factor and min BER at ONU 3 for downstream $1480 \mathrm{~nm}$ wavelength for mechanism type C

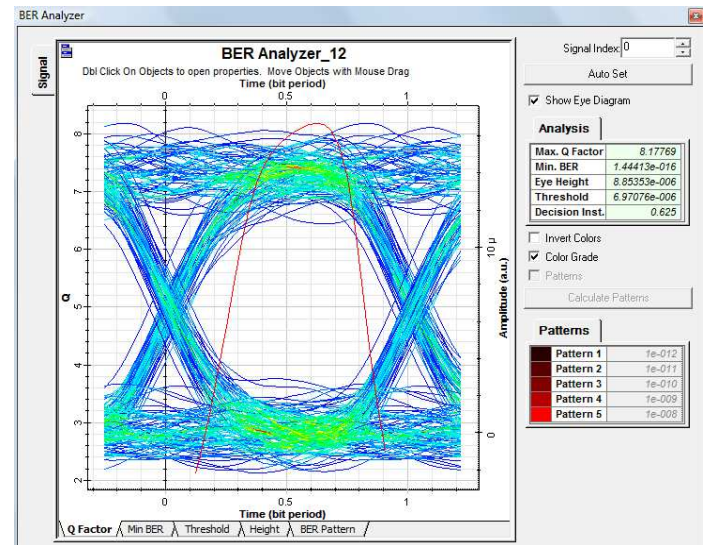

Max Q factor $=7.42866 ;$ Min BER $=5.46005 \mathrm{e}-14$

(a)

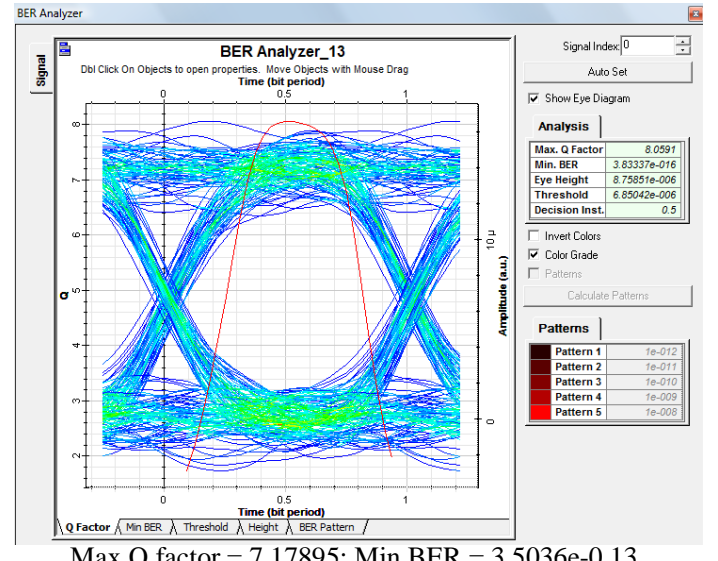

(b)

Fig. 11: (a): Max Q factor and min BER at ONU 4 for downstream $1550 \mathrm{~nm}$ wavelength; (b): Max $\mathrm{Q}$ factor and min BER at ONU 4 for downstream $1480 \mathrm{~nm}$ wavelength.

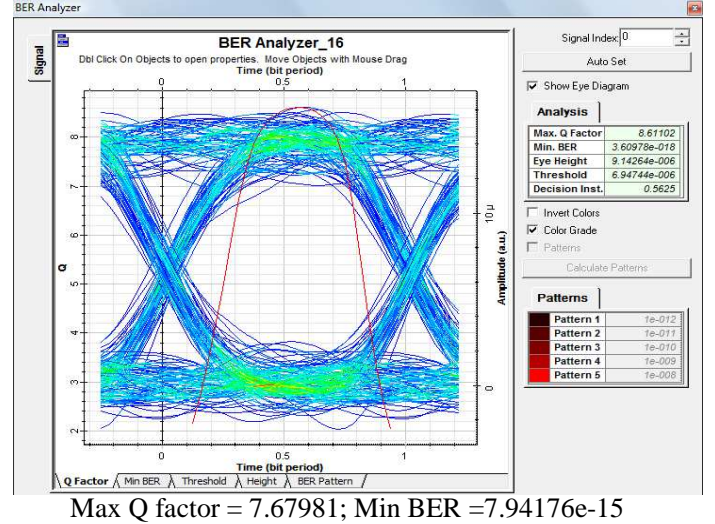

(a)

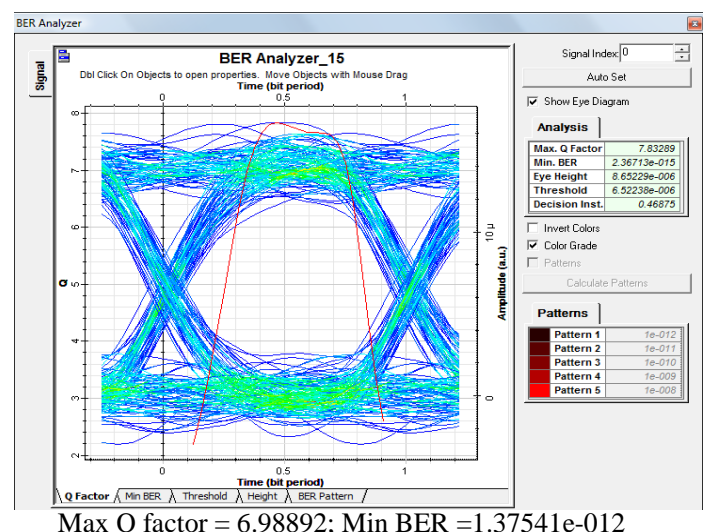

(b)

Fig. 12: (a): Max Q factor and min BER at ONU 5 for downstream $1550 \mathrm{~nm}$ wavelength; (b): Max $\mathrm{Q}$ factor and min BER at ONU 5 for downstream $1480 \mathrm{~nm}$ wavelength 


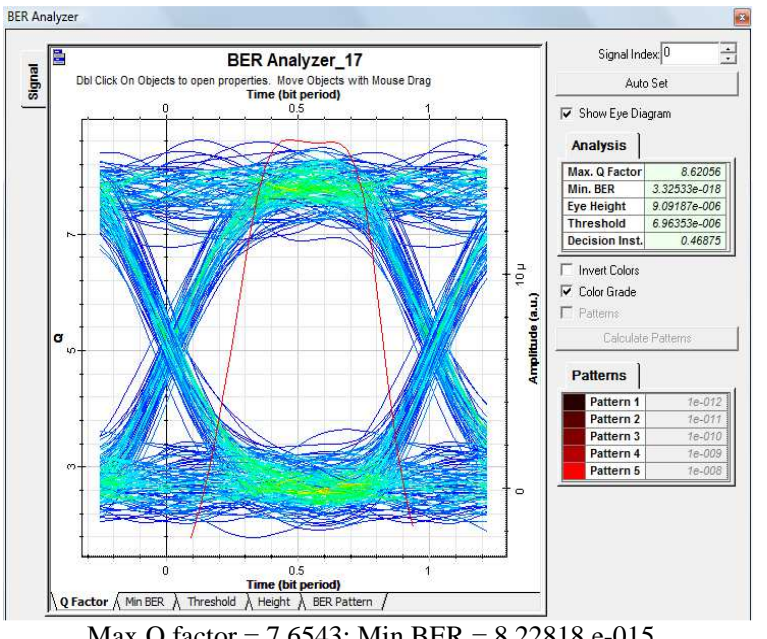

Max $\mathrm{Q}$ factor $=7.6543 ;$ Min BER $=8.22818$ e-015

(a)

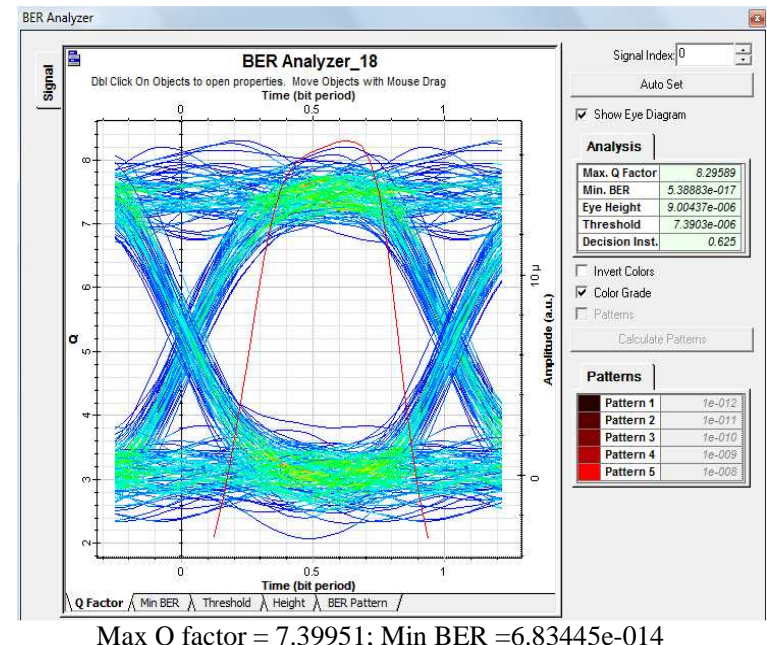

(b)

Fig. 13: (a): Max Q factor and min BER at ONU 6 for downstream 1550nm wavelength; (b): Max Q factor and min BER at ONU 6 for downstream 1480nm wavelength.

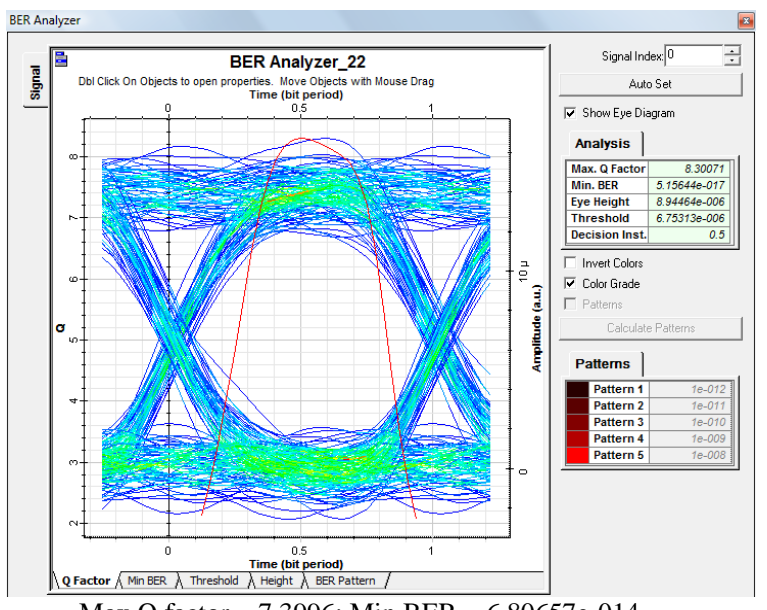

Max Q factor $=7.3996 ;$ Min BER $=6.80657 \mathrm{e}-014$

(a)

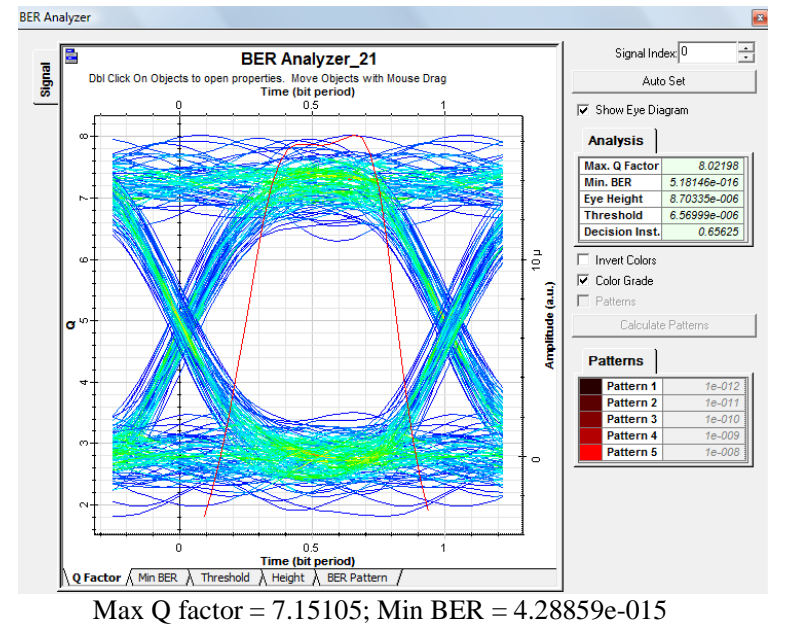

(b)

Fig. 14: (a): Max Q factor and min BER at ONU 7 for downstream $1550 \mathrm{~nm}$ wavelength; (b): Max $\mathrm{Q}$ factor and min BER at ONU 7 for downstream $1480 \mathrm{~nm}$ wavelength.

Figure 13 represents the eye diagram at ONU 6 when the optic signal has been converted to the protection path, when a failure occurs at the working line. While Fig. 14 depicted the eye diagram for optic signal in normal condition that pass through the working line directly to the receiver (ONU 7).

\section{DISCUSSION}

There is no major difference with other architectures in terms of cost of ONU and OLT equipments. The major difference lies on the fiber usage among the architectures ${ }^{[7]}$. Our FTTH design architecture used only $20 \mathrm{~km}$ of fiber optic length. The costs of a FTTH deployment will be depending on a lot of parameters. All the geographical and demographical parameters will have a very large impact on the costs. Due to different number of optical switch that was used in every type of failure mechanism, then it will result in different value of receive power for every mechanism. Analyzing the system in ideal condition (insertion loss of switches are equal to $0 \mathrm{~dB}$ ), the values of $\mathrm{Q}$ factor can be accepted and above the minimum requirement which is $6\left(\sim\right.$ BER $\left.=1 \times 10^{-9}\right)$ was achieved for every 
type of protection mechanism to prove the system feasibility when employed the dedicated protection and shared protection scheme. According to the four failure types which is type $\mathrm{A}, \mathrm{B}, \mathrm{C}$ and $\mathrm{D}$ the protection route will involve in two, four, six and eight numbers of optical switch respectively. In actual condition, for every number of optical switches, the insertion loss is considered equal to $1.2 \mathrm{~dB}$ and the values must be considered in the calculation. Our results show the values are acceptable at the receiver sensitivity of $-35 \mathrm{dBm}$. This will be addressed in our next publication.

\section{CONCLUSION}

The survivability of EPON is necessary to provide seamless services and ensure network reliability. The protection scheme is purposely design for immediate split architecture that can be applied in apartments, small offices and outlets which share one building. Single failure in the line connected will activate dedicated protection while shared protection is activated when both fiber (working and standby fiber) are breakdown. The simulation model and the results were presented to convince proposed protection scheme. In this paper, we represented the simulation design approach for the ideal condition when no loss of optical switches is considered. The BER characteristics were measured at $1.25 \mathrm{Gbps}$ and no degradation was observed, as confirmed by a comparison of these simulation results with those obtained from systems without restoration element. ACS will responsible to monitor signal section and sensing fault location and activate the optical switches according to the failure conditions. The proposed protection scheme was simple but capable of diverting the signal to alternative path up to three failures condition. So, the survivability in network will add redundant capacity, detect faults and automatically re-route traffic around the failure. So the mechanism of protection for the system was designed to meet the network specification.

\section{ACKNOWLEDGEMENT}

This project is supported by Ministry of Science, Technology and Environment, Malaysia Government, through the National E-Science Project fund 01-01-02SF0493 and Research University Grant fund UKMGUP-TMK-07-02-108.

\section{REFERENCE}

1. Heard, I.B., 2008. Availability and cost estimation of secured FTTH architectures. Proceeding of the IEEE International Conference on Optical Network Design and Modeling, Mar. 12-14, IEEE Xplore Press, USa., pp: 1-6. DOI: 10.1109/ONDM.2008.4578390

2. Hossain, D., H. Erkan, R. Dorsinville, M. Ali, A. Sami and C. Assi, 2005. Protection for ringbased EPON architecture. Proceeding of the 2nd International Conference on Broadband 7-7, IEEE Xplore Press, Boston, MA., USA., pp: 1548-1553. DOI: 10.1109/ICBN.2005.1589790

3. Tzanakaki, A., I. Zacharopoulus and I. Tomkos, 2003. Optical Add/drop multiplexers and optical cross-connects for wavelength routed network. Proceeding of the 5th International Conference on Transparent Optical Networks, June 29-July 3, Warsaw, Poland, pp: 41-46. DOI: 10.1109/ICTON.2003.1264574

4. Koonen, T., 2006. Fiber to the home/ fiber to the premise: What, where and when? Proc. IEEE., 94: 911-934. DOI: 10.1109/JPROC.2006.873435

5. Tsushima, H., S. Hanatani, T. Kanetake, J.A. Fee and S.A. Liu, 1998. Optical cross-connect system for survivable optical layer networks. Proceeding of the Conference and Exhibit on Optical Fiber Communication, Feb. 22-27, Technical Digest, San Jose, CA., USA., pp: 271-272. DOI: 10.1109/OFC.1998.657390

6. Ab-Rahman, M.S., A.A. Ehsan and S. Shaari, 2006. Self-protected passive optical network using Access Control System (ACS). Proceeding of the 5th International Conference on Optical Communications and Networks 2nd International Symposium on Advances and Trends in Fiber Optics and Applications, (ICOCN/ATFO'06), Chengdu, China, pp: 335-341.

7. Casier, K., S. Verbrugge, R. Meersman, D. Colle, M. Pickavet and P. Demeester, 2008. Technoeconomic evaluations of FTTH roll-out scenarious. Proceeding of the 13th European Conference on Networks and Optical Communications, July 2008, Belgium, pp: 113-120. http://en.scientificcommons.org/37857372 